\title{
Application of the FDA Biosimilar Extrapolation Framework to Make Off-Label Determinations
}

\author{
Edward Li, PharmD, MPH, BCOP, and Ernesto Lobaina, PharmD Candidate
}

\begin{abstract}
BACKGROUND: The FDA's extrapolation framework allows for a biosimilar to obtain licensure for indications that were not explicitly studied in the context of a clinical trial by extending conclusions from studies in 1 population to make inferences in other populations. Within routine clinical care, drugs and biologics are routinely used for medically accepted off-label indications. The appropriateness of these products for off-label indications are typically curated by compendia and guidelines, which have established processes and criteria for reviewing and evaluating the evidence to make such determinations. The evidence paradigm for biosimilars is different from originator biologics and is one of comparability to a reference product, not to reestablish clinical benefit. Thus, this paradigm shift can be applied to the exercise of making off-label determinations for biosimilars, and the FDA's framework of extrapolation can be used by clinicians and coverage policy decision makers to determine appropriate off-label indications for biosimilars.
\end{abstract}

OBJECTIVE: To highlight how the FDA's biosimilar extrapolation framework can be used to make off-label policy decisions, using to 2 approved biosimilars for filgrastim and infliximab as case studies.

METHODS: This study describes the FDA extrapolation framework for evaluating whether there are any differences in the mechanism of action, pharmacokinetics/biosdistribution, immunogenicity, and toxicity between on-label and off-label indications. Two case studies are presented that evaluate the biosimilars filgrastim-sndz and infliximab-dyyb for the offlabel indications of treating symptomatic anemia in patients with myelodysplastic syndromes and immune-mediated colitis, respectively. The analytical, nonclinical, and clinical pharmacology, along with clinical studies demonstrating that filgrastim-sndz and infliximab-dyyb are biosimilar to their respective reference products, are reviewed and discussed in context with the extrapolation framework to ascertain whether use of the biosimilar within the off-label indications is scientifically justified.

RESULTS: The mechanism of action of filgrastim and infliximab between their FDA-approved and off-label indications are the same. In addition, there is a high degree of similarity with the analytical and nonclinical characteristics of filgrastim-sndz and infliximab-dyyb and their respective reference products. There is no expectation of differences in safety and immunogenicity across the patient populations. Thus, some decision makers may determine that filgrastim-sndz and infliximab-dyyb be used for the off-label indications of treating symptomatic anemia in patients with myelodysplasia and immune-mediated colitis, respectively.

CONCLUSIONS: In some cases, the use of biosimilars for off-label indications can be scientifically justified. Since coverage policy decisions are intimately tied to compendia and guideline listings, it is incumbent upon these groups to conduct formal assessments of biosimilar off-label indications using the FDA extrapolation framework.

J Manag Care Spec Pharm. 2017;23(12):1227-32

Copyright $\odot 2017$, Academy of Managed Care Pharmacy. All rights reserved.

\section{What is already known about this subject}

The FDA currently has a framework that allows for extrapolation of FDA-approved indications of the reference product when not explicitly studied in clinical trials of the biosimilar.

Stakeholders who make off-label decisions do not receive guidance from the regulatory authority or the biosimilar manufacturer as to whether off-label indications are appropriate and justified; however, the FDA's extrapolation framework can be used by stakeholders to help make these determinations.

\section{What this study adds}

This study applies the biosimilar extrapolation framework used by the regulatory authorities to make decisions about off-label indications to the biosimilars filgrastim-sndz and infliximab-dyyb. Compendia and guidelines currently rely on case reports and observational studies to consider strength and level of evidence for off-label recommendations of reference drugs and biologics. The FDA's extrapolation framework is a new assessment method for making off-label determinations when specifically evaluating biosimilars

1 he use of drugs and biologics for indications beyond the labeling approved by the U.S. Food and Drug Administration (FDA), that is, "off-label prescribing," is an accepted practice, specifically in the therapeutic areas of pediatrics, oncology, or other rare diseases where options are generally limited. ${ }^{1}$ For example, in recent population-based reports, the prevalence of off-label prescribing of chemotherapy has been reported to be between 30\%-64\%.,3 Off-label use may come in many forms, such as dosing, schedule, and duration of administration, and indication of use may differ from the FDA-approved labeling. The cause for concern with off-label prescribing is that the regulatory authority has not explicitly reviewed the product for efficacy and safety within the off-label indications, potentially questioning whether the benefits of the therapy outweigh the risks. However, off-label use can be supported if based on available evidence that meets specific standards, which were not part of the product's FDA registration package, along with an assessment of the severity of the disease. ${ }^{4}$ For example, the Grading of Recommendations, Assessment, Development and Evaluations (GRADE) Working group has developed a method for rating the quality of evidence and linking it to clinical recommendations. ${ }^{5}$ 
Accordingly, the Centers for Medicare \& Medicaid Services (CMS) rely on federally recognized compendia as the curators of this evidence and to set coverage policy decisions for Medicare Part D drugs and anticancer therapies. These compendia include the American Hospital Formulary Service-Drug Information, Truven Health Analytics Micromedex DrugDEX, the National Comprehensive Cancer Network (NCCN) Drugs and Biologics Compendium, Elsevier/Gold Standard Clinical Pharmacology, and Wolters Kluwer Clinical Drug Information Lexi-Drugs. ${ }^{6,7}$ To be recognized by CMS, these compendia had to meet certain criteria that included having a transparent process for reviewing the evidence that justifies a recommendation. ${ }^{7}$ Under the evidence paradigm for novel drugs and biologics, the minimal evidence for listing a recommendation is typically based on phase 2 and phase 3 trials.

The introduction of biosimilars into practice creates a quandary for stakeholders, who evaluate off-label indications and set utilization or coverage policies based on a review of the evidence, primarily because the review paradigms for generic small molecule drugs and for originator biologics do not apply to these agents. ${ }^{8}$ For generic small-molecule products, off-label determinations are not based on clinical studies that evaluate the generic product within a specific indication. Rather, the conclusions based on the clinical evidence for the reference product can be extended to the generic product because regulations require that the generic's active pharmaceutical agent be identical to the reference product, with studies demonstrating no clinically and statistically meaningful differences in bioavailability. Likewise, the biosimilarity regulatory exercise is to demonstrate high similarity to the reference product, with no clinically meaning differences, not to reestablish clinical benefit (i.e., efficacy and safety).

Biosimilars earn the FDA-approved labeling for the reference product's approved indications when the biosimilar sponsor makes sufficient "scientific justification" that conclusions from the limited population studied in the clinical trial can be extended to additional indications being sought. This process is known, from a regulatory standpoint, as extrapolation, and it is based on the biosimilar totality of the evidence plus what is known about the reference product. ${ }^{9-11}$ The framework for extrapolation is based on an evaluation of potential differences with the mechanism of action across indications, pharmacokinetics and biodistribution, safety, immunogenicity, or other factors that affect safety and efficacy for each indication and patient population..$^{9-11}$ We propose that this exercise can also be applied by clinicians and policymakers when considering off-label indications for biosimilars.

The purpose of this study was to demonstrate how the extrapolation framework used to infer the use of biosimilars for FDA-approved indications can be applied to an evidence review process for off-label indications by presenting case studies involving 2 FDA-approved biosimilars, infliximab-dyyb and filgrastim-sndz, and their extrapolation for immune-related colitis and myelodysplastic syndromes (MDS), respectively.

\section{Methods}

For the 2 case studies, a literature review was conducted to gather and interpret data in context with the FDA extrapolation framework to ascertain whether use of the biosimilars within off-label indications could be similarly scientifically justified. In addition, briefing documents submitted by the sponsors to the FDA advisory committees were reviewed to determine whether any differences in the mechanism of action, pharmacokinetics and biodistribution, immunogenicity, and toxicity across on-label indications would affect the evaluation of infliximab-dyyb and filgrastim-sndz for the off-label indications of immune-mediated colitis and the treatment of MDS, respectively.

Studies describing the mechanism of action across indications, as well as those that compared the physicochemical and functional characteristics of filgrastim-sndz and infliximabdyyb with their reference products, were also reviewed. Other domains of the totality of the biosimilar evidence were also reviewed, including safety reports (including immunogenicity), efficacy, and any other potential factors that could affect immunogenicity.

Data collected were meant to answer 2 questions within each of the following domains of the extrapolation exercise: mechanism of action (target/receptor, binding, dose/concentration response, relationship between structure and target/ receptor interactions, and location of target/receptor); pharmacokinetics and biodistribution parameters; adverse events; and immunogenicity. The questions were as follows: (1) What is known to be the differences (if any) between the on-label indications and off-label indications for the reference product? and (2) How does the totality of the evidence with the biosimilar affect the differences (if any) of the reference product?

Based on a review of the information, a recommendation of whether the biosimilar may be used for the off-label indication is provided.

\section{Results}

\section{Filgrastim-sndz: Extrapolation to the Treatment} of Neutropenia Associated with MDS

Filgrastim is a myeloid growth factor that the FDA approved for the prevention of chemotherapy-induced febrile neutropenia. Filgrastim reduces the time to neutrophil recovery following induction for acute myelogenous leukemia (AML) and chemotherapy for stem cell transplantation (SCT), mobilizes autologous hematopoietic progenitor cells, reduces the duration and consequences of congenital or idiopathic neutropenia, and increases survival in patients exposed to myeosuppressive radiation. ${ }^{12}$ Filgrastim is recombinant human granulocyte-colony stimulating factor (G-CSF) that binds to the G-CSF receptor on 


\begin{tabular}{|c|c|c|c|}
\hline Domain & $\begin{array}{l}\text { What Is Known About the } \\
\text { Reference Product Between On-Label } \\
\text { and Off-Label Indications }\end{array}$ & What Is Known About the Biosimilar & Conclusion \\
\hline $\mathrm{MOA}$ & $\begin{array}{l}\text { There is a single receptor (G-CSFR) by } \\
\text { which G-CSF mediates its effect; the pro- } \\
\text { duction of mature neutrophils is the same } \\
\text { for neutropenia due to cytotoxic chemo- } \\
\text { therapy and for myleodysplasia }{ }^{13,25}\end{array}$ & $\begin{array}{l}\text { Filgrastim-sndz is highly similar to refer- } \\
\text { ence filgrastim; functional studies confirm } \\
\text { that the binding affinity is comparable } \\
\text { between products } 26\end{array}$ & $\begin{array}{l}\text { Filgrastim-sndz is expected to stimulate } \\
\text { the production of mature neutrophils to the } \\
\text { same degree as the reference product }\end{array}$ \\
\hline $\begin{array}{l}\text { PK and } \\
\text { biodistribution }\end{array}$ & $\begin{array}{l}\text { Clearance is mediated by neutrophils and } \\
\text { bioavailability increases during periods of } \\
\text { neutropenia; early PK studies of the refer- } \\
\text { ence and biosimilar typically included } \\
\text { healthy volunteers }{ }^{18}\end{array}$ & $\begin{array}{l}\text { Studies of healthy volunteers (a more sensi- } \\
\text { tive population as recognized by the FDA) } \\
\text { demonstrated that filgrastim-sndz is bio- } \\
\text { equivalent to reference filgrastim }{ }^{26,27}\end{array}$ & $\begin{array}{l}\text { The PK and biodistribution of filgrastim- } \\
\text { sndz is expected to be the same as the refer- } \\
\text { ence product for patients with MDS }\end{array}$ \\
\hline Safety & $\begin{array}{l}\text { Major adverse effects of filgrastim include } \\
\text { injection site pain and bone pain } 12\end{array}$ & $\begin{array}{l}\text { The safety profile of filgrastim-sndz is simi- } \\
\text { lar to that of the reference product }{ }^{16}\end{array}$ & $\begin{array}{l}\text { There are no expected additional safety risks } \\
\text { with filgrastim-sndz in patients with MDS }\end{array}$ \\
\hline Immunogenicity & $\begin{array}{l}\text { The overall immunogenicity of filgrastim is } \\
\text { low } 12\end{array}$ & $\begin{array}{l}\text { The overall immunogenicity of filgrastim- } \\
\text { sndz is similarly as low as the reference } \\
\text { product } 16,26\end{array}$ & $\begin{array}{l}\text { There are no expected additional immu- } \\
\text { nogenicity risks with filgrastim-sndz in } \\
\text { patients with MDS }\end{array}$ \\
\hline $\begin{array}{l}\text { Other supportive } \\
\text { factors }\end{array}$ & $\begin{array}{l}\text { Reports indicate that mutations in the } \\
\text { G-CSFR may influence the development of a } \\
\text { leukemic transformation } 28\end{array}$ & $\begin{array}{l}\text { As previously indicated, the bioactivity of } \\
\text { filgrastim-sndz is highly similar to that of } \\
\text { the reference product } 26\end{array}$ & $\begin{array}{l}\text { There are many distinct mechanisms that } \\
\text { confer a defect in the maturation of neu- } \\
\text { trophils; filgrastim-sndz is not expected to } \\
\text { influence these pathways any more than the } \\
\text { reference product }\end{array}$ \\
\hline
\end{tabular}

FDA =U.S. Food and Drug Administration; G-CSFR=granulocyte-colony stimulating receptor; $M D S=$ myelodysplastic syndromes; $M O A=$ mechanism of action; sPK= pharmacokinetics.

progenitor cells, stimulating neutrophil proliferation and differentiation..$^{13}$ According to the NCCN guidelines for MDS, filgrastim may be used in addition to an erythropoiesis-stimulating agent or lenalidomide for some patients with symptomatic anemia (category $2 \mathrm{~A}$ recommendation). ${ }^{14}$

Filgrastim-sndz is an approved biosimilar to filgrastim, with analytic studies demonstrating that it is highly similar to its reference, pharmacokinetics studies demonstrating bioequivalence, and pharmacodynamic and clinical comparative studies showing no clinical differences in the duration of severe neutropenia in a population of breast cancer patients receiving myelosuppressive chemotherapy. ${ }^{15,16}$ Based on the totality of the biosimilar data and scientific justification, filgrastimsndz earned extrapolation to reducing the time to neutrophil recovery following induction for AML and chemotherapy for SCT, mobilizing autologous hematopoietic progenitor cells, and reducing the duration and consequences of congenital or idiopathic neutropenia (indications for which the marketing exclusivity had expired). ${ }^{17}$ While the current NCCN guidelines mention G-CSF products, use of filgrastim-sndz explicitly for this indication is not specified. Accordingly, we applied the FDA biosimilar extrapolation framework to the symptomatic treatment of anemia in patients with MDS, which is outlined in Table 1.

Based on the assessment of the domains, filgrastim-sndz was expected to stimulate the production of mature neutrophils to the same degree as its reference, with a similar pharmacokinetics and biodistribution, safety, and immunogenicity profile as its reference drug within the population of MDS patients. Therefore, clinicians and coverage policymakers may consider the use of filgrastim-sndz for the treatment of symptomatic anemia in patients with MDS to be scientifically justified. The totality of the biosimilar data, coupled with the relatively simple mechanism of action, pharmacokinetics, and biodistribution of the molecule leads to the assessment that the efficacy and risk of using the biosimilar within MDS is the same as the reference. Although there are concerns regarding leukemic transformation within this patient population, this is mostly related to genetic factors and within individual patient germ lines. ${ }^{18}$ Thus, the risk of leukemic transformation is not expected to be greater with the biosimilar than it is for the reference product.

\section{Infliximab-dyyb: Extrapolation to the Treatment of Immune-Mediated Colitis}

Infliximab is a tumor necrosis factor (TNF) inhibitor that the FDA approved for Crohn's disease (adult and pediatric), ulcerative colitis (adult and pediatric), rheumatoid arthritis (in combination with methotrexate), ankylosing spondylitis, psoriatic arthritis, and plaque psoriasis. ${ }^{19}$ According to published case studies and reports, infliximab has been successfully used to treat immune-mediated (e.g., ipilimumab, nivolumab, and pembrolizumab) colitis, and it is typical for treatment protocols to include infliximab for situations of severe colitis 
TABLE 2 Scientific Justification for Use of Infliximab-dyyb in Treatment of Immune-Mediated Colitis

\begin{tabular}{|c|c|c|c|}
\hline Domain & $\begin{array}{l}\text { What Is Known About the } \\
\text { Reference Product Between On-Label } \\
\text { and Off-Label Indications }\end{array}$ & What Is Known About the Biosimilar & Conclusion \\
\hline$\overline{\mathrm{MOA}}$ & $\begin{array}{l}\text { The primary MOA of infliximab for } \\
\text { ipilimumab-mediated colitis is the block- } \\
\text { ade of TNF, which reduces neutrophil } \\
\text { recruitment to the colon while maintaining } \\
\text { tumor activity } 29\end{array}$ & $\begin{array}{l}\text { Based on bioactivity studies, the TNF } \\
\text { blockade with infliximab-dyyb is highly } \\
\text { similar to that of the reference product } 30,31\end{array}$ & $\begin{array}{l}\text { Infliximab-dyyb is expected to produce the } \\
\text { same anti-TNF magnitude and effects as the } \\
\text { reference product in ipilimumab-induced } \\
\text { colitis }\end{array}$ \\
\hline $\begin{array}{l}\mathrm{PK} \text { and } \\
\text { biodistribution }\end{array}$ & $\begin{array}{l}\text { In a PK study with infliximab in patients } \\
\text { with lung cancer, chemotherapy and can- } \\
\text { cer did not appear to affect the serum con- } \\
\text { centrations of infliximab32 }\end{array}$ & $\begin{array}{l}\text { Infliximab-dyyb has been demonstrated to } \\
\text { be bioequivalent to the reference product } 33\end{array}$ & $\begin{array}{l}\text { There are no additional concerns with } \\
\text { the PK of infliximab products in patients } \\
\text { with lung cancer, and this conclusion can } \\
\text { be extended to patients with other tumor } \\
\text { types; therefore, the PK and biodistribution } \\
\text { of infliximab-dyyb is expected to be the } \\
\text { same as the reference product }\end{array}$ \\
\hline Safety & $\begin{array}{l}\text { Common adverse effects are related to } \\
\text { infections and infusion-related reactions, } \\
\text { as well as significant long-term toxicities of } \\
\text { hepatotoxicity, malignancies, and serious } \\
\text { infections }{ }^{19}\end{array}$ & $\begin{array}{l}\text { Adverse effects with infliximab-dyyb were } \\
\text { similar to that of the reference product in } \\
\text { clinical studies } 34\end{array}$ & $\begin{array}{l}\text { With only } 2 \text { doses of infliximab adminis- } \\
\text { tered for patients with ipilimumab-induced } \\
\text { colitis, the development of long-term serious } \\
\text { adverse effects is not a concern }\end{array}$ \\
\hline Immunogenicity & $\begin{array}{l}\text { The development of ADA to infliximab is a } \\
\text { general concern }{ }^{19}\end{array}$ & $\begin{array}{l}\text { There were no differences in ADA develop- } \\
\text { ment with infliximab-dyyb compared with } \\
\text { the reference product }{ }^{34}\end{array}$ & $\begin{array}{l}\text { With only 1-2 doses of infliximab adminis- } \\
\text { tered for patients with ipilimumab-induced } \\
\text { colitis, the development of ADA is generally } \\
\text { not a concern }\end{array}$ \\
\hline $\begin{array}{l}\text { Other supportive } \\
\text { factors }\end{array}$ & $\begin{array}{l}\text { Infliximab for immune-mediated colitis } \\
\text { has not been vigorously tested }\end{array}$ & $\begin{array}{l}\text { Infliximab-dyyb is highly similar with } \\
\text { no clinical differences to the reference } \\
\text { product }^{30,31,34}\end{array}$ & $\begin{array}{l}\text { Infliximab-dyyb should not be expected to } \\
\text { meet a standard that was not met by the } \\
\text { reference product (e.g., prospective, ran- } \\
\text { domized trials) in this indication }\end{array}$ \\
\hline
\end{tabular}

when patients are being treated with these agents..$^{20,21}$ While most compendia do not list infliximab for this indication, the NCCN Guidelines for Melanoma recommend infliximab as the "preferred" treatment for severe immune-related colitis that does not respond to steroids (category $2 \mathrm{~A}$ recommendation). ${ }^{22}$

Infliximab-dyyb is an approved biosimilar of infliximab, with the totality of the evidence demonstrating that it is highly similar to the reference product with no clinically meaningful differences. ${ }^{23}$ In the data application submitted to the FDA, the clinical comparative trial demonstrated equivalence to the reference product in patients with rheumatoid arthritis who also received methotrexate..$^{24}$ Based on the data and scientific justification, the FDA allowed extrapolation to the reference product's other FDA-approved indications for which the marketing exclusivity has expired. ${ }^{11}$ This extrapolation excluded the pediatric ulcerative colitis indication. In the NCCN guidelines, there is no mention about whether infliximab-dyyb may be used as another option in treating patients with immunemediated colitis. ${ }^{22}$ In this context, the FDA biosimilar extrapolation framework was applied to this off-label indication, which is outlined in Table 2.

Based on this assessment, there is no indication that using infliximab-dyyb would produce different clinical results in patients with immune-mediated colitis compared with its reference product. Therefore, clinicians and coverage policymakers may consider that the use of infliximab-dyyb in the treatment of immune-mediated colitis is scientifically justified. This determination is based on the similarity of the mechanism of action (i.e., TNF blockade) across indications and the lack of effect on infliximab pharmacokinetics within a cancer population. The totality of the evidence with the biosimilar makes the case that infliximab-dyyb is an appropriate option in this setting. It should be noted that the recommendation for using reference infliximab in this situation is based mostly on lowerquality evidence (e.g., case reports), and prospective randomized trials to demonstrate safety and efficacy are nonexistent. It is, therefore, unreasonable to expect that the biosimilar will have prospective, randomized, and controlled studies to support its use for this off-label indication.

\section{Discussion}

In this review, we presented 2 cases where off-label use of biosimilars was evaluated using the FDA's framework of extrapolation. In these cases, it is our opinion that these off-label indications for the biosimilars may be scientifically justified based on what is currently understood about the reference biologic in context with the totality of the evidence that supports the biosimilar exercise. This type of review is important because these indications are clinically valid uses of the reference product, and both indications are for situations with a relatively 
low incidence of use. Accordingly, robust clinical trials using the biosimilar (or reference product) are unlikely to come to fruition. All stakeholders must feel confident about using a product for an indication, and this exercise performed by clinicians, compendia, and other coverage policymakers will help to instill confidence in the use of biosimilar products. To that end, rather than expecting that a biosimilar would produce the same type and amount of data that allowed the reference product to earn its recommendation for an off-label indication, it is recommended that the formulary and coverage policy decision makers use the FDA's extrapolation framework to consider offlabel indications for biosimilars.

\section{Limitations}

There are several limitations to the approach described in this review, most of which revolve around a lack of evidence. In certain situations, there could be missing or a lack of data that fully characterizes the differences between indications for the reference product, especially in characterizing the mechanism of action within the off-label indications and for understanding pharmacokinetic differences across populations. Lack of data is likely to become an ongoing issue because off-label use could be based more on clinical experience with less development in the basic sciences than for on-label indications. One must consider the ramifications when there is a paucity of information.

For novel drugs and biologics, the default position, in the absence of data, is to act conservatively and not use the therapy, while waiting for more evidence. With biosimilars, it is less clear whether this conservative approach should be used. Since the regulatory exercise assessed the comparability of the biosimilar to the reference product (and not clinical benefit), the absence of clinical data does not necessarily mean that a biosimilar is not comparable to its reference product. Therefore, it will be essential for decision makers to make the rationale for their off-label determinations as transparent as possible.

Another limitation to making off-label determinations using the extrapolation framework is the relative inexperience that clinicians have with evaluation of data, information, and evidence that makes up the most important aspect of the biosimilarity exercise: the analytical comparisons of the physicochemical and functional characteristics. Previous survey data indicate that clinicians may place more weight on the clinical trials of biosimilars. Therefore, it is important for all stakeholders to understand the biosimilarity exercise and the importance of the analytical exercise.

An interesting challenge highlighted in the case studies occurs when the off-label use of the reference product is based on lower-quality evidence (e.g., case studies), and there are no prospective trials supporting its use. In these situations, the recommendation for off-label use is likely based on a calculation of the severity and urgency of the situation plus a strong theoretical basis for efficacy (such as the mechanism of action), which is exemplified by the use of infliximab for immune-mediated colitis. In these situations, the risk-benefit calculation could favor the determination that the biosimilar should also be used for the indication because the severity of the situation would require patients to have greater access to potentially life-saving therapies. Increasing the options available through biosimilars serves to increase access to care.

\section{Conclusions}

Coverage policy decisions are based on a review of the level of evidence supporting an indication, and decision makers recognize compendia and professional society guidelines in their evaluation of the evidence. The extrapolation framework that the FDA uses to extend approval conclusions to other indications not explicitly studied in a clinical trial serves as a mechanism for stakeholders to make off-label determinations. Accordingly, stakeholders who review biosimilars for off-label consideration (such as pharmacy \& therapeutics committees, compendia, and managed care organizations) should review current evaluation processes to ensure balanced and fair assessments of off-label use of biosimilars and incorporate a review of the key elements (mechanism of action, pharmacokinetics, safety, and immunogenicity) considered in extrapolation of FDA-approved indications, as shown in the case studies presented in this study. This exercise will be an important factor in increasing biosimilar adoption in the United States.

\section{Authors}

EDWARD LI, PharmD, MPH, BCOP, and ERNESTO LOBAINA, PharmD Candidate, University of New England College of

Pharmacy, Portland, Maine.

AUTHOR CORRESPONDENCE: Edward Li, PharmD, MPH, BCOP, University of New England College of Pharmacy, 716 Stevens Ave., Portland, ME 04103. Tel.: 207.221.4120; E-mail: eli@une.edu.

\section{DISCLOSURES}

No outside funding supported this study. Li discloses that he has received honoraria and/or paid travel expenses as an advisory board and speaker's bureau participant for Pfizer; for speaking on behalf of Mylan and Apobiologix; and for participating on advisory boards for Eli Lilly and Mylan. Lobaina has nothing to disclose.

Li was responsible for study design and manuscript revision. Li took the lead in data collection and interpretation and manuscript preparation, along with Lobaina.

\section{REFERENCES}

1. Levêque D. Off-label use of anticancer drugs. Lancet Oncol. 2008;9(11):1102-07.

2. Conti RM, Bernstein AC, Villaflor VM, et al. Prevalence of off-label use and spending in 2010 among patent-protected chemotherapies in a population-based cohort of medical oncologists. J Clin Oncol. 2013;31(9):1134-39. 
3. Eaton AA, Sima CS, Panageas KS. Prevalence and safety of off-label use of chemotherapeutic agents in older patients with breast cancer: estimates from SEER-Medicare data. J Natl Compr Canc Netw. 2016;14(1):57-65.

4. McGivney WT. The issue is "off-evidence," not "off-label." J Natl Compr Canc Netw. 2006;4(6):529-30.

5. Alonso-Coello P, Oxman AD, Moberg J, et al. GRADE Evidence to Decision (EtD) frameworks: a systematic and transparent approach to making well informed healthcare choices. 2: Clinical practice guidelines. BMJ. 2016;353:i2089.

6. Centers for Medicare \& Medicaid Services. Medicare prescription drug benefit manual. Chapter 6-Part D drugs and formulary requirements. 2016 Available at: https://www.cms.gov/Medicare/Prescription-Drug-Coverage/ PrescriptionDrugCovContra/Downloads/Part-D-Benefits-Manual-Chapter-6. pdf. Accessed October 7, 2017

7. Centers for Medicare \& Medicaid Services. Medicare benefit policy manual. Chapter 15-covered medical and other health services. 2017. Available at: https://www.cms.gov/Regulations-and-Guidance/Guidance/Manuals/ Downloads/bpl02c15.pdf. Accessed October 7, 2017.

8. Ventola CL. Biosimilars: part 1: proposed regulatory criteria for FDA approval. P T. 2013;38(5):270-87.

9. Weise M, Kurki P, Wolff-Holz E, et al. Biosimilars: the science of extrapolation. Blood. 2014;124(22):3191-96.

10. U.S. Food and Drug Administration. Scientific considerations in demonstrating biosimilarity to a reference product. Guidance for industry. April 2015. Available at: https://www.fda.gov/downloads/drugs/guidances/ ucm291128.pdf. Accessed October 7, 2017.

11. Tesser JR, Furst DE, Jacobs I. Biosimilars and the extrapolation of indications for inflammatory conditions. Biologics. 2017;11:5-11.

12. Neupogen (filgrastim) injection, for subcutaneous or intravenous use. Amgen. Revised June 2016. Available at: http://pi.amgen.com/ /media/ amgen/repositorysites/pi-amgen-com/neupogen/neupogen_pi_hcp_english. pdf. Accessed October 7, 2017.

13. Bendall LJ, Bradstock KF. G-CSF: from granulopoietic stimulant to bone marrow stem cell mobilizing agent. Cytokine Growth Factor Rev. 2014;25(4):355-67.

14. Greenberg PL, Stone RM, Al-Kali A, et al. Myelodysplastic Syndromes, Version 2.2017, NCCN Clinical Practice Guidelines in Oncology. J Natl Compr Canc Netw. 2017;15(1):60-87.

15. U.S. Food and Drug Administration. FDA approves first biosimilar product Zarxio. FDA News release. March 6, 2015. Available at: https://www.fda. gov/newsevents/newsroom/pressannouncements/ucm436648.htm. Accessed October 7, 2017.

16. Blackwell K, Semiglazov V, Krasnozhon D, et al. Comparison of EP2006, a filgrastim biosimilar, to the reference: a phase III, randomized, doubleblind clinical study in the prevention of severe neutropenia in patients with breast cancer receiving myelosuppressive chemotherapy. Ann Oncol. 2015;26(9):1948-53

17. Sandoz. FDA approves first biosimilar Zarxio (filgrastim-sndz) from Sandoz. March 6, 2015. Available at: https://www.sandoz.com/news/mediareleases/fda-approves-first-biosimilar-zarxiotm-filgrastim-sndz-sandoz. Accessed October 7, 2017.

18. Welte K, Gabrilove J, Bronchud MH, et al. Filgrastim (r-metHuG-CSF): the first 10 years. Blood. 1996;88(6):1907-29.
19. Remicade (infliximab) lyophilized concentrate for injection, for intravenous use. Janssen Biotech. Revised November 2013. Available at: https:// www.accessdata.fda.gov/drugsatfda_docs/label/2013/103772s5359lbl.pdf. Accessed October 7, 2017.

20. Arriola E, Wheater M, Karydis I, et al. Infliximab for IPILIMUMABrelated colitis-letter. Clin Cancer Res. 2015;21(24):5642-43.

21. O'Connor A, Marples M, Mulatero C, et al. Ipilimumab-induced colitis: experience from a tertiary referral center. Therap Adv Gastroenterol. 2016;9(4):457-62

22. National Comprehensive Cancer Network. NCCN Clinical Practice Guidelines in Oncology. Melanoma (version 1.2017). Available at: https:// www.nccn.org/professionals/physician_gls/f_guidelines.asp\#site. Accessed October 7, 2017

23. U.S. Food and Drug Administration. FDA approves Inflectra, a biosimilar to Remicade. FDA news release. April 5, 2016. Available at: https:// www.fda.gov/newsevents/newsroom/pressannouncements/ucm494227.htm. Accessed October 7, 2017.

24. Yoo DH, Racewicz A, Brzezicki J, et al. A phase III randomized study to evaluate the efficacy and safety of CT-P13 compared with reference infliximab in patients with active rheumatoid arthritis: 54-week results from the PLANETRA study. Arthritis Res Ther. 2016;18:82.

25. Steensma DP. Hematopoietic growth factors in myelodysplastic syndromes. Semin Oncol. 2011;38(5):635-47.

26. Sörgel F, Schwebig A, Holzmann J, et al. Comparability of biosimilar filgrastim with originator filgrastim: protein characterization, pharmacodynamics, and pharmacokinetics. BioDrugs. 2015;29(2):123-31.

27. U.S. Food and Drug Administration. Clinical pharmacology data to support a demonstration of biosimilarity to a reference product. Guidance for industry. December 2016. Available at: https://www.fda.gov/downloads/ drugs/guidancecomplianceregulatoryinformation/guidances/ucm397017.pdf. Accessed October 7, 2017.

28. Beekman R, Touw IP. G-CSF and its receptor in myeloid malignancy. Blood. 2010;115(25):5131-36.

29. Minor DR, Chin K, Kashani-Sabet M. Infliximab in the treatment of anti-CTLA4 antibody (ipilimumab) induced immune-related colitis. Cancer Biother Radiopharm. 2009;24(3):321-25.

30. Jung SK, Lee KH, Jeon JW, et al. Physicochemical characterization of Remsima. MAbs. 2014;6(5):1163-77.

31. Fang J, Doneanu C, Alley WR Jr, et al. Advanced assessment of the physicochemical characteristics of Remicade and Inflectra by sensitive LC/MS techniques. MAbs. 2016;8(6):1021-34.

32. Jatoi A, Jett JR, Sloan J, et al. A pilot study on safety and pharmacokinetics of infliximab for the cancer anorexia/weight loss syndrome in non-smallcell lung cancer patients. Support Care Cancer. 2004;12(12):859-63.

33. Park W, Lee SJ, Yun J, et al. Comparison of the pharmacokinetics and safety of three formulations of infliximab (CT-P13, EU-approved reference infliximab and the US-licensed reference infliximab) in healthy subjects: a randomized, double-blind, three-arm, parallel-group, single-dose, phase I study. Expert Rev Clin Immunol. 2015;11(Suppl 1):S25-31.

34. Radin M, Sciascia S, Roccatello D, et al. Infliximab biosimilars in the treatment of inflammatory bowel diseases: a systematic review. BioDrugs. 2017:31(1):37-49. 